\title{
Fornix lesions: Effects on active and passive avoidance behavior
}

\author{
JOHN de CASTRO and THOM W. HALL \\ University of Massachusetts, Amherst, Massachusetts 01002
}

\begin{abstract}
Twenty-four fornix-lesioned and 16 sham-operated rats were tested on one-way active avoidance acquisition, subsequent passive avoidance of the previously safe compartment, and acquisition and extinction of the passive avoidance of an electrified foodcup. Rats with lesions of the fornix made significantly more errors than controls in learning the one-way active avoidance acquisition task and had significantly elevated freezing scores on both escape and avoidance trials. Lesioned animals also made significantly more errors in the passive avoidance of the previously safe compartment. There were no significant differences found on either acquisition or extinction of the passive avoidance of an electrified foodcup. The results support the hypothesis that fornix destruction produces impaired performance on tasks which require a spatial discrimination.
\end{abstract}

Performance on avoidance tasks has been found to be altered following destruction of the hippocampus (Douglas, 1967; Kimble, 1968). However, results have been inconsistent, due probably to variation in lesion placement and to the type of avoidance task used. Four distinctly different lesion placements have been used: total hippocampus, ventral hippocampus, dorsal hippocampus, or fornix. Lesions of each of these sites within the hippocampus produces its own characteristic set of behavioral alterations (Coscina, 1967; Fried, 1971; Liss, 1968; Nadel, 1968). Also, a large variety of avoidance tasks have been employed. Passive avoidance is a case in point. Three general categories, with many variations upon the general theme, can be identified on the basis of the response to be withheld: stop approaching, stop avoiding, and stop exploring. Differential results have been obtained depending upon which type of task and which lesion placement was used (Coscina, 1967; Fried, 1971; Kaada, Rasmussen, \& Kveim, 1962; Liss, 1968; McNew \& Thompson, 1966; Nadel, 1968).

In the following study, the lesion-placement variable was held constant (fornix), and its effect upon one-way active avoidance acquisition and two passive avoidance tasks (stop approaching and stop avoiding) was assessed.

\section{METHOD}

\section{Subjects}

The subjects were 40 Sprague-Dawley male albino rats purchased from the Holtzman Company. They were between 60 and 150 days of age at the time of surgery and weighed between 280 and $480 \mathrm{~g}$.

\section{Surgery and Histology}

Surgery was performed under sodium pentobarbital anesthesia

This research was supported in part by NIMH Training Grant in Experimental Psychology (MH 11823). The assistance of E. E. Krieckhaus and $J$. W. Moore is gratefully acknowledged. John de Castro is now at Georgia State University, Atlanta, Georgia 30303. Thom W. Hall is now at University of Denver, Denver, Colorado.
$(40 \mathrm{mg} / \mathrm{kg}$ administered IP) and atropine methyl nitrate $(.75 \mathrm{mg})$ was administered to suppress mucosal secretion. A series of five radio-frequency lesions (Grass LM-4) were produced by passing $90 \mathrm{~mW}$ power for $50 \mathrm{sec}$ through Size 00 insect pins insulated with Teflon except for a $.5-\mathrm{mm}$ tip at $1.4 \mathrm{~mm}$ posterior to bregma, $5.1 \mathrm{~mm}$ below the surface of the skull, and $0, .7$, and $1.7 \mathrm{~mm}$ to either side of the midsaggital sinus. Sham operations used exactly the same procedure except no current was passed.

Following testing, the lesioned animals were perfused with $10 \%$ formalin. The brains were removed, imbedded in gelatin, sectioned at 50 micron and stained with a modified Weigert procedure (Wolf, 1971).

\section{Apparatus}

The stop-approaching passive avoidance training occurred in a $20 \times 35 \times 20 \mathrm{~cm}$ Plexiglas chamber. Access to a small Plexiglas feeding chamber, $8 \times 8 \times 6 \mathrm{~cm}$, was allowed via a circular hole, $7 \mathrm{~cm}$ in diam, with a manually operated guillotine door. The stainless steel floor of the waiting room was connected through a constant-current shock source to the stainless steel bottom of the foodcup in the middle of the small feeding chamber. A $750-\mathrm{V}$ ac shock source in series with a 1-megohm resistance produced a maximum current of $.75 \mathrm{~mA}$.

A two-compartment shuttlebox, equipped with a grid floor, was used for active avoidance testing. Each compartment was $32.5 \times 29 \times 30 \mathrm{~cm}$ with a guillotine door separating the two compartments. A .6 mA scrambled shock was applied through the grid floor. The CS was a $1,000-\mathrm{Hz}$ tone generated by an Ameco code practice oscillator and speaker located $85 \mathrm{~cm}$ above the middle of the shuttlebox.

\section{Procedure}

After a 7-day postoperative recovery period, the subjects were divided into four groups on the basis of age and weight. For one group of fornix-lesioned animals $(\mathrm{N}=12)$ and one sham-operated group $(\mathrm{N}=8)$, stop-approaching passive avoidance training was run first, followed by active avoidance acquisition and reversal (passive-active groups). The other lesioned group $(\mathrm{N}=12)$ and the other sham-operated group $(N=8)$ received active avoidance acquisition and reversal training first, followed by stop-approaching passive avoidance training (active-passive groups). Following the completion of the first task, sufficient time to regain pretraining body weights (with a minimum of 2 days) was given before the next task began.

Training on the stop-approaching task was preceded by a $48-\mathrm{h}$ period of food deprivation. Moist powdered lab chow was present in the testing chamber. Throughout training, food was 
restricted to that which was obtained during testing. Following a 5-min adaptation period, the animals were trained to approach and eat from the foodcup as soon as the guillotine door was raised. Two or three bites of the moist lab chow was allowed on each trial, and there was a 5-sec intertrial interval. Each animal was run daily for 30 min until a criterion of five consecutive trials with a median latency of less than $5 \mathrm{sec}$ was achieved. Immediately following the criterion trials, the foodcup was electrified and training continued until the rat avoided the food for 10 consecutive minutes. The following day, reacquisition training commenced with the shock turned off. On the trial following criterion reacquisition, the foodcup was again electrified, and a single shock was given. Training continued with the shock off for 10 trials or for $15 \mathrm{~min}$ if the animal did not return to the food.

One-way active avoidance acquisition training began following a 1-min exploration period in the shuttlebox. A standard response terminated procedure was used. Each trial consisted of a 10-sec pre-CS period, raising the guillotine door and CS onset, a 10 -sec CS-US interval, closing of the guillotine door and CS offset, a 10-sec post-CS period, and removal of the rat by hand from the safe compartment and placement in the start compartment. Latency to cross and freezing scores were recorded on each trial. Freezing scores, on a scale of one to four, were taken during the 10 -sec pre-CS period, the CS-US interval, and the post-CS period. A rating of one was given for movement of all four paws, a two for movement of the front paws only, a three for head and neck movement only, and four for no movement. Ten trials were given on the 1 st day and 20 trials on all subsequent days until a criterion was reached of 17 or more avoidance responses in a single session in conjunction with 8

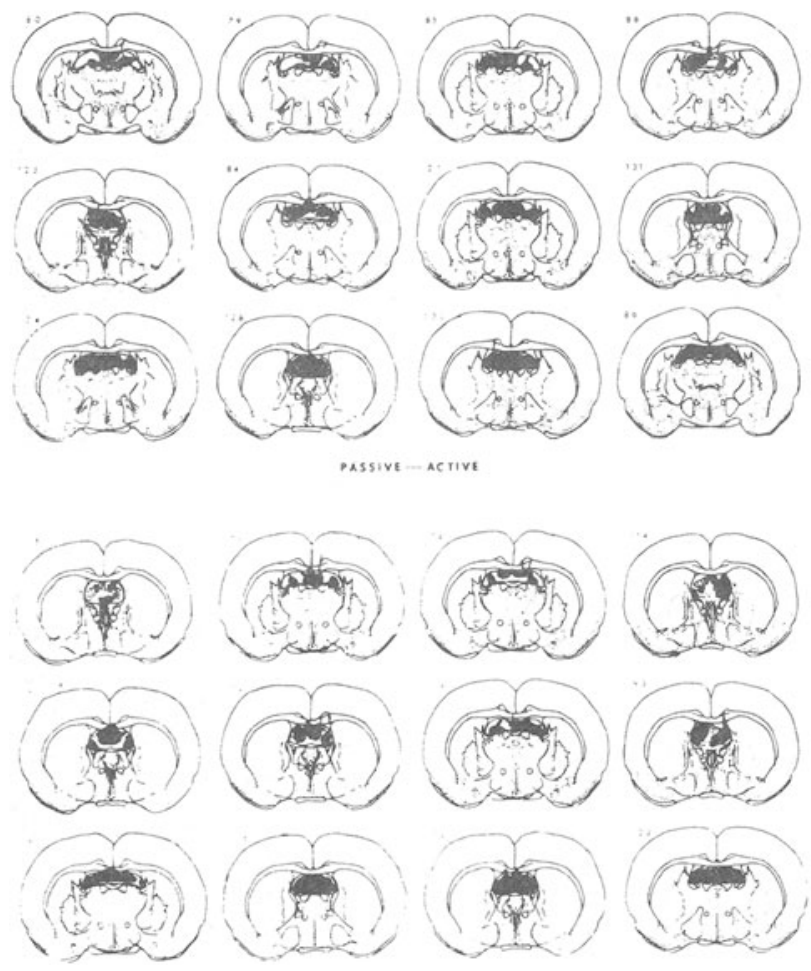

Figure 1. Reconstructions of the maximum extent of the damage to the fornix for all lesioned animals in both groups. avoidance responses out of the first 10 trials on the following day. On the 11 th trial, the compartment in which the shock appeared was reversed such that the floor of the previously safe compartment was now electrified. Trials proceeded as before with CS-US termination and door closure as soon as the rat returned to the start compartment or after $30 \mathrm{sec}$ if the rat did not cross. Latencies to cross and to return were recorded. A total of 10 reversal trials were given.

\section{RESULTS}

\section{Histology}

Drawings of the maximum damage for each lesioned animal are presented in Figure 1. Damage consistently occurred in the fornix posterior to the septo-fimbrial area and anterior to the dorsal hippocampus. Damage to surrounding structures was slight, inconsistent, and not correlated with any of the principal behavioral measures.

\section{Avoidance Behavior}

Fornicotomy impaired one-way active avoidance acquisition. Lesioned animals incurred a greater number of shocks before attaining the acquisition criterion than the sham-operated animals $[F(1,36)=5.47, p<.025]$. This deficit was evident even in the first acquisition session $[\mathrm{t}(38)=2.12, \mathrm{p}<.05]$ before any break in training occurred (Figure 2). Furthermore, although prior training in the stop-approaching task significantly reduced the number of shocks to criterion $[F(1,36)=10.15, p<.005]$, it did so for both groups and did not obscure the effect of the lesion.

Fornicotomy resulted in heightened freezing scores (Figure 3) both on escape trials $[\mathrm{F}(1,36)=8.31$, $\mathrm{p}<.01]$ and on avoidance trials $[\mathrm{F}(1,36)=6.54$, $\mathrm{p}<.025]$. Even though the fornix-lesioned animals were more prone to freeze than the sham-operated animals, there was no difference between the groups on either their latencies to avoid or their latencies to escape. Thus, fornicotomy induced a deficiency in one-way active avoidance acquisition and accentuated the freezing response but did not affect the response latency.

One passive avoidance task (stop avoiding) was affected by the lesion while the other (stop approaching) was not (Figure 2). Fornix-lesioned rats took significantly more shocks than sham-operated rats before learning to withhold the well-established one-way active avoidance response $[F(1,36)=7.20, p<.025]$. In contrast, there were no significant effects found on any of the measures of acquisition, extinction, or reacquisition in the stop-approaching task. Thus, while fornix-lesioned animals had difficulty learning to withhold an avoidance response, they did not have difficulty learning to withhold an approach response.

\section{DISCUSSION}

Fornicotomy resulted in deficient acquisition of 

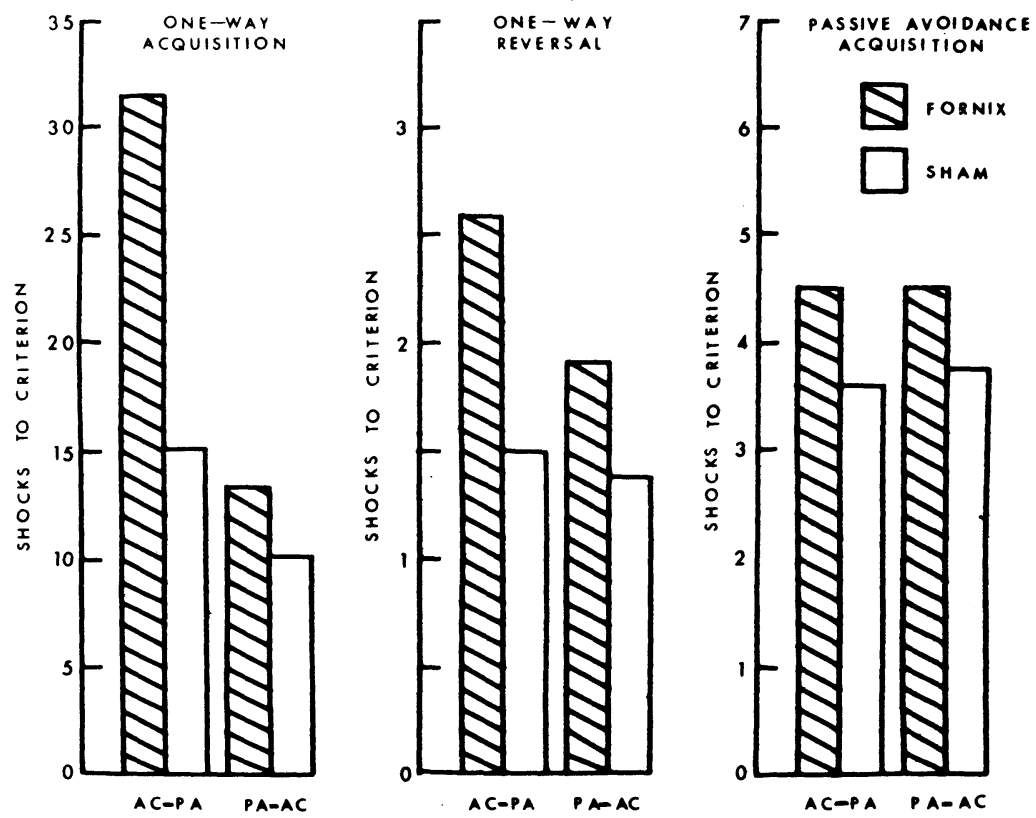

Figure 2. The mean number of shocks taken to attain the learning criterion in one-way active avoidance acquisition and in the two passive avoidance tasks by both lesion and control groups. (AC-PA active-passive groups, PA-AC passive-active groups)

one-way active avoidance responding and in its subsequent reversal. Liss (1968) also found these deficiencies but only when trials were spaced and not when they were massed. In the present study, one-way acquisition was deficient on the first day of testing and one-way reversal was run in a single massed session, indicating a massed trial deficit. It is possible that the placement of the lesion was the critical variable. Liss's lesions only damaged the lateral aspects of the fornix and thus mainly severed fibers originating in the ventral hippocampus. Lesions of the ventral hippocampus do

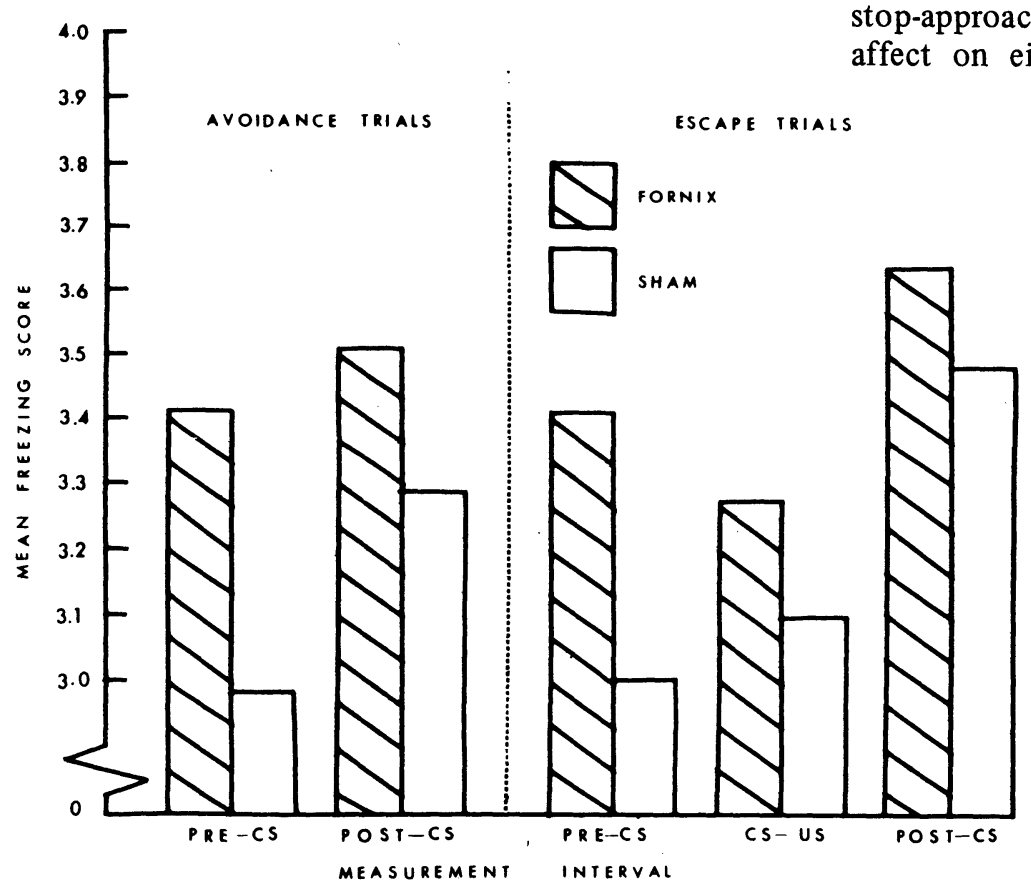

not produce deficits in either one-way avoidance acquisition or its subsequent reversal (Coscina, 1967; Liss, 1968; Nadel, 1968). In the present study, damage occurred in all aspects of the fornix and thus severed fibers originating throughout the hippocampus. Total hippocampal destruction results in deficiencies on both of these tasks (Coscina, 1967; McNew \& Thompson, 1966; Olton \& Isaacson, 1968). Thus, these discrepant results appear to be accounted for by differences in the damage to the fornix.

Fornix lesions did not affect the extinction of the stop-approaching task as reflected by the lack of a lesion affect on either the trials to reacquire the approach
Figure 3. The mean freezing scores on avoidance trials and on escape trials for the lesion and control groups during each of the three 10-sec measurement intervals. (Note: The CS-US interval freezing score for avoidance trials is, by definition, 1.0.) 
response or the latency to return to the food following shock. This essentially replicates previous findings (Van Hoeson, MacDougall, \& Mitchell, 1969; Van Hoeson, Wilson, MacDougall, \& Mitchell, 1972). That fornix lesions do not affect either the acquisition or the reacquisition of the avoidance response has not been previously reported.

There are a number of possible hypotheses to explain these effects. It is possible that the primary effect of the lesion is to heighten freezing and the deficit in active avoidance acquisition is a secondary consequence. This is doubtful, however, because a heightened freezing response would tend to increase the likelihood of not crossing. Hence, a facilitation of one-way reversal performance should have occurred rather than the observed deficit. It is also possible that the main effect of the lesion was to reduce fear. However, the observed increase in freezing behavior suggests increased rather than decreased fear. In addition, decreased fear should produce more casual responding and thus produce an increase in avoidance latencies. In fact, no significant differences between lesion and control groups were observed in avoidance latencies.

Response inhibitory theories (McCleary, 1966) cannot account for these data. The fact that fornix-lesioned rats are just as capable as controls at inhibiting an approach response argues against such an interpretation. Also, a deficit in one-way active avoidance acquisition simply cannot be explained in terms of response inhibition.

It has recently been proposed (Samuels, 1972) that hippocampal lesions produce a deficit specific to spatial discriminations. The data on the effects of fornicotomy on behavior are compatible with this notion. Animals with lesions of the fornix were found, in the present study, to be deficient in shuttlebox tasks wherein the animal must discriminate safe from dangerous places, while they were not deficient in the avoidance of an electrified foodcup wherein the animal must only discriminate that the foodcup is dangerous. Hence, the pattern of results discerned in the present experiment can be accounted for on the basis of a lesion-induced impairment in spatial discriminative ability.

The effect of fornix lesions on maze performance also supports this notion. Fornix lesions have been shown to produce deficits in the reversal of position habits (Fischman \& McCleary, 1966; Hirsh \& Segal, 1972; Uretsky \& McCleary, 1969) and, on a task in which position and turn could be separated, fornix lesions were found to impair selectively both the acquisition and reversal of a position discrimination (de Castro, 1974). In addition, fornix lesions disrupt performance in complex mazes (Kaada, Rasmussen, \& Kveim, 1962; Thomas, 1971).
Thus, the results of the present study, as well as previous research, on the effects of fornicotomy on behavior, suggests that the primary behavioral deficit resultant from the damage is an impairment in the animal's ability to perform spatial discriminations. What facet of this complex discrimination is disrupted is not known. It has been suggested, however, that fornix lesions impair the long-term storage and/or retrieval of information concerning spatio-temporal sequences of stimuli (de Castro, 1974).

\section{REFERENCES}

Coscina, D. V. The effects of differential hippocampal lesions on a shock vs. shock conflict. Unpublished masters thesis, Bucknell University, 1967.

deCastro, J. M. A selective spatial discrimination deficit after fornicotomy in the rat. Behavioral Biology, 1974, 12, 373-382.

Douglas, R. J. The hippocampus and behavior. Psychological Bulletin, 1967, 67, 416-442.

Fischman, M., \& McCleary, R. A. Patterned perseveration deficits following fornicotomy in the cat. Cited by $R$. A McCleary. Response modulating functions of the limbic system: Initiation and suppression. In E. Stellar and J. M. Sprague (Eds.), Progress in physiological psychology (Vol. 1). New York: Academic Press, 1966, 209-272.

Fried, P. A. Limbic system lesions in rats: Differential effects in an approach-avoidance task. Journal of Comparative and Physiological Psychology, 1971, 74, 349-353.

Hirsh, R., \& Segal, M. Complete transection of the fornix and reversal of position habit in the rat. Physiology and Behavior, 1972, 8, 1051-1054.

Kaada, B. R., Rasmussen, E. W., \& Kveim, O. Impaired acquisition of passive avoidance behavior by subcallosal, septal, hypothalamic and insular lesions in rats. Journal of Comparative and Physiological Psychology, 1962, 55, 661-670.

Kimble, D. P. The hippocampus and internal inhibition. Psychological Bulletin, 1968, 70, 285-295.

Liss, P. Avoidance and freezing behavior following damage to the hippocampus or fornix. Journal of Comparative and Physiological Psychology, 1968, 66, 193-197.

McCleary, R. A. Response modulating functions of the limbic system: Initiation and suppression. In E. Stellar and J. M. Sprague (Eds.), Progress in Physiological Psychology (Vol. 1). New York: Academic Press, 1966, 209-272.

McNew, J. J., \& Thompson, R. Role of the limbic system in active and passive avoidance conditioning in the rat. Journal of Comparative and Physiological Psychology, 1966, 61, 173-180.

Nadel, L. Dorsal and ventral hippocampal lesions and behavior. Physiology and Behavior, 1968, 3, 891-900.

Olton, D. L., \& Isaacson, R. L. Hippocampal lesions and active avoidance. Physiology and Behavior, 1968, 3, 719-724.

Samuels, I. Hippocampal lesions in the rat: Effects on spatial and visual habits. Physiology and Behavior, 1972, 8, 1093-1098.

Thomas, G. J. Maze retention by rats with hippocampal lesions and with fornicotomies. Journal of Comparative and Physiological Psy chology, 1971, 75, 41-49.

Uretsky, E., \& McCleary, R. A. Effect of hippocampal isolation on retention. Journal of Comparative and Physiological Psychology, 1969, 68, 1-8.

Van Hoesen, G. W., MacDougall, J. M., \& Mitchell, J. C. Anatomical specificity of septal projections in active and passive avoidance conditioning. Journal of Comparative and Physiological Psychology, 1969, 68, 80-89.

Van Hoesen, G. W., Wilson, L. M., MacDougall, J. M., \& Mitchell, J. C. Selective hippocampal complex deafferentation and deeferentation and avoidance behavior in rats. Physiology and Behavior, 1972, 8, 873-879.

Wolf, G. Elementary histology for neuropsychologists. In R. D. Myers (Ed.), Methods in Psychobiology. New York: Academic Press, 1971, 281-300. (Received for publication November 11, 1974; revision received November 25,1974 .) 